\title{
Crash and Wait? The Impact of the Great Recession on the Retirement Plans of Older Americans
}

\author{
By BROOKE HELPPIE MCFALL*
}

In 2008, the confluence of the financial crisis, the stock market crash, and the housing bust ushered in the "Great Recession." The stock market crash of 2008 caused massive, largely unanticipated, and widespread losses of wealth over a period of just a few months. While stock market declines in past decades have disproportionately affected the relatively wealthy stock-holding class, the increasing prevalence of defined contribution pensions has exposed a much broader set of older adults to stock market risk in the most recent economic downturn. Compounding the effect of large stock market losses, plummeting real estate values and the weakening labor market further reduced older Americans' stocks of wealth between 2008 and 2009.

When facing an unforeseen negative shock to assets, a standard intertemporal budget constraint from a life cycle model with retirement choice dictates that individuals must increase labor supply, reduce planned consumption, or adjust both labor supply and consumption. The stock and real estate market losses of the recent crash present an ideal quasi-experiment for testing whether retirement plans react to wealth shocks in a way consistent with a life cycle model with retirement choice.

\footnotetext{
* McFall: University of Michigan, Department of Economics, 611 Tappan Street, Ann Arbor, MI 48104 (e-mail: bhelppie@umich.edu). The author gratefully acknowledges support from the National Institute on Aging (NIA P01-AG10179). Also, thanks to Robert J. Willis, Matthew Shapiro, Miles Kimball, David Weir, Joanne Hsu, Matthew Rutledge, and participants at seminars at the University of Michigan Department of Economics and the Health and Retirement Study Workin-Progress seminar for their suggestions and support, and for data and advice from Alan Gustman, Nahid Tabatabai, Kandice Kapinos, and Helena Stolyarova.
}

In this paper, I use data from the Cognitive Economics (CogEcon) ${ }^{1}$ study to examine the impact of recent wealth losses on the retirement plans of the general population of older Americans. This research is the first to use new data from fortuitously-timed pre- and postcrash surveys by CogEcon to study the impact of wealth shocks on the age at which older adults expect to retire. Using reduced-form regression techniques, I provide estimates of the relationship between wealth losses and changes in retirement planning.

The data show that a large proportion of participants in the CogEcon study reported changing their expected retirement age "as a result of the economic crisis." My preferred regression estimates imply that the average wealth loss between July 2008 and May/June 2009 is associated with an increase in expected retirement age of approximately 2.5 months. This increase in expected retirement age is even larger for individuals who are pessimistic about future stock returns.

\section{Data and Methods}

\section{A. Data}

CogEcon is a mail- and web-based survey project designed by a group of economists at the Survey Research Center at the University of Michigan. The original goal of the study was to explore the relationship between cognitive measures and economic decision-making

\footnotetext{
${ }^{1}$ The CogEcon study was developed by the NIA program project P01-AG026571 under the leadership of Robert J. Willis. University of Michigan faculty Gwenith G. Fisher, Miles Kimball, Matthew Shapiro, and Tyler Shumway, plus graduate students Joanne W. Hsu and the author helped design and field the CogEcon study. The sample frame is from the CogUSA project (NIA R37 AG007137) led by John J. McArdle of the University of Southern California.
} 
among older Americans. The baseline survey was fielded to a nationally representative sample older Americans between spring and summer 2008, and attained responses from 987 individuals.

In early 2009, after it became clear that the economic crisis was having widespread effects, the study team obtained supplemental funding from the NIA to design and field a "PostCrash" survey to measure these effects. The resulting survey was fielded between mid-May and late June 2009, and received responses from 848 baseline survey respondents.

Sample.-This paper uses data from both the baseline and "Post-Crash" waves of CogEcon. The sample used in this paper is restricted to the 306 respondents who: (i) were at least 40 years old at the time of the baseline survey, (ii) reported a labor force status of "working now" at the time of the Post-Crash survey, (iii) were not "completely retired" by the time of the Post-Crash survey, (iv) reported pre-July 2008 planned retirement ages at least as large as their ages in July 2008, (v) reported earnings in either the baseline or Post-Crash survey, and (vi) provided at least some information about wealth holdings and wealth changes in the Post-Crash survey.

In this sample, 51.6 percent of respondents are female and 22.1 percent are single. The mean education level is 14.9 years, the mean age 60.5 years, and median annual labor earnings are $\$ 52,023$.

Calculated variables.-To create the measures of wealth losses and changes in retirement age used in my analyses, I follow work by Purvi Sevak (2002) in using a "sustainable consumption" metric. An individual's sustainable consumption is the annuity that could be purchased in 2009 using all current financial and real estate wealth plus the expected present discounted value of future labor, Social Security and defined benefit pension income.

Losses in sustainable consumption due to wealth losses between mid-2008 and mid-2009 reflect changes in respondents' attainable material standard of living, holding expected future income streams constant. For example, a 2 percent change in sustainable consumption represents a permanent 2 percent loss in a respondent's material standard of living. With this measure, I implicitly assume that individuals prefer to smooth consumption perfectly over time.

To create the variables used in this study, I first calculate individual $j$ 's sustainable consumption from 2009, the year of the PostCrash survey as $S C_{j, t}=\left(A_{j, t}+Y_{j}\right) / a_{j}$, where $t \in\{2008,2009\}$ indicates whether pre-crash (July 2008) or post-crash (May/June 2009) measures of wealth are used. The numerator is a measure of total wealth: $A_{j, t}$ represents assets held by individual $j$ 's household at time $t$, and includes wealth held in checking, savings, money market accounts, bonds, mutual funds, stocks and real estate (excluding primary homes), while $Y_{j}$ is the expected present discounted value of the household's income flows from 2009 until death, and includes imputed values for: labor earnings, Social Security, and defined benefit pensions. ${ }^{2}$ The denominator, $a_{j}$, is a conventionally-calculated annuitization factor, and reflects the price at which individual $j$ could purchase an annuity in 2009 that would pay the equivalent of one 2009 dollar per year until death. ${ }^{3}$

The pre-crash sustainable consumption level, $S C_{j, 08}$, is therefore the (counterfactual) consumption level that could have been sustained by individual $j$ from 2009 through the end of life, had the wealth losses from fall 2008 through spring 2009 not occurred. ${ }^{4}$ Similarly, $S C_{j, 09}$ is the consumption level that could be sustained given reported 2009 wealth levels, while holding expected future income streams

\footnotetext{
${ }^{2}$ See Appendix for more detail.

${ }^{3}$ Load factor $\mathrm{L}=0.18$ is chosen from estimates by Olivia $\mathrm{S}$. Mitchell et al. (1999), individual-level age- and sexspecific survival probabilities are calculated from life tables (SSA 2006), and following Alan Gustman, Thomas Steinmeier and Nahid Tabatabai (2010), I use inflation and nominal interest rates $\pi=0.028$ and $\mathrm{i}=0.058$.

${ }^{4}$ Except for bonds, which are held constant, pre-crash components of wealth are imputed using reported levels of wealth holdings in 2009 and reported changes since July 2008. Analyses by the CogEcon team have shown that the retrospective measures appear to be less noisy than the true panel data, while matching up well in aggregate.
} 
unchanged as a result of the crash.

A measure of individual $j$ 's wealth loss due to stock and real estate wealth losses between fall 2008 and spring 2009 is then calculated using the equation:

$$
\% \Delta S C_{j}=\left(\frac{S C_{j, 09}-S C_{j, 08}}{S C_{j, 08}}\right) \times 100
$$

This is the percent change in individual $j$ 's sustainable consumption level due to stock and real estate wealth losses.

To create the independent variable of interest, I first calculate $R_{j, S C O 8},{ }^{5}$ the retirement age that would be necessary for individual $j$ to regain the pre-crash sustainable consumption level, $S C_{j, 08}$. Finally, the independent variable of interest, $\Delta R_{j, S C 08}$, is the difference between individual $j$ 's reported planned retirement age as of July 2008 and the age at which this individual could retire while maintaining precrash sustainable consumption levels.

The dependent variable, $\Delta R_{j}$, is calculated as the difference between the May/June 2009 planned retirement age and the retrospectively reported July 2008 retirement age. ${ }^{6}$

\section{B. Methods}

The regression results presented here are from the Tobit specification:

$$
\text { (1) } \Delta R_{j}^{*}=\alpha+\beta \Delta R_{j, S C 08}+\gamma\left(\Delta R_{j, S C 08}\right)^{2}+u_{j}
$$

which requires the distributional assumption $u_{j} \mid \Delta R_{j, S C 08} \sim N\left(0, \sigma^{2}\right)$.

This specification was chosen based on the empirical observation that there is a large mass at zero change in reported retirement age, indicating that most individuals did not adjust their planned retirement ages between July 2008 and May/June 2009. This is not

\footnotetext{
${ }^{5}$ Detail on calculation of this variable can be found in the Appendix.

${ }^{6}$ Questions about retirement age were asked towards the beginning of the survey, and before any questions about wealth losses. This should reduce priming bias, although, because respondents were asked whether the age at which they expect to retire had changed "as a result of the economic crisis," framing bias may be a concern.
}

surprising, given that many individuals did not lose large amounts of wealth in the crash. However, it is also plausible that there are fixed costs of changing retirement plans due to emotional costs of changing plans, effort costs to re-optimize retirement decisions, and/or rigidities in employment relationships and pension rules. These costs may have prevented some individuals from adjusting their planned retirement ages. The censoring point for results reported in this paper is zero, ${ }^{7}$ so the observed dependent variable is $\Delta \mathrm{R}_{\mathrm{j}}=\max \left(0, \Delta R_{j}{ }^{*}\right)$.

\section{Results}

Descriptive Analysis.-As a first step toward understanding the impact of the crisis on older Americans' wealth holdings, I first examined the incidence of the crash using the calculated variable $\% \Delta S C_{j}$. This variable measures the percent change in sustainable consumption experienced by respondents between July 2008 and May/June 2009. The first two columns of Table 1 show that the average loss in sustainable consumption over this period was 5.8 percent, but varied from a gain of 2.4 percent in the least negatively affected quintile of respondents, to a 21.0 percent loss in the quintile of respondents that was most impacted by the crash.

The third and fourth columns of Table 1 show the number of years by which respondents would have to delay retirement to make up the losses completely, $\Delta R_{j, S C 08}$. The average respondent would need to work an additional 2.38 years, but the necessary adjustments range from decreasing retirement age by more than one year for the least affected quintile. Among those in the middle quintile, the average adjustment is just 0.81 years, while those in the most affected quintile would need to work an average of 8.61 additional years.

Finally, the fifth and sixth columns of Table 1 describe $\Delta R_{j}$, reported changes in retirement age. The average reported change is 1.56 years, and within-quintile averages increase monotonically from the first through the fourth quintiles before declining sharply in the

\footnotetext{
${ }^{7}$ Results are robust to censoring at 1 , rather than 0 .
} 
TABLE 1 -SUSTAINABLE CONSUMPTION AND RETIREMENT AGE, BY QUINTILES OF PERCENT CHANGE IN SUSTAINABLE CONSUMPTION

\begin{tabular}{lcccccc}
\hline Quintiles of percent change in sustainable consumption, $\left(\% \Delta S C_{j}\right)$ & \multicolumn{2}{c}{$\% \Delta S C_{j}$} & \multicolumn{3}{c}{$\Delta R_{j, S C 08}$} & \multicolumn{2}{c}{$\Delta R_{j}$} \\
\hline & Median & Mean & Median & Mean & Median & Mean \\
\hline 1 (least negatively affected) & 0.7 & 2.4 & -0.02 & -1.25 & 0 & 1.43 \\
2 & -0.2 & -0.2 & 0.03 & -0.06 & 0 & 1.52 \\
3 & -2.1 & -2.5 & 0.62 & 0.81 & 0 & 1.59 \\
4 & -7.7 & -7.5 & 1.95 & 3.69 & 1 & 2.01 \\
5 (most negatively affected) & -18.1 & -21.0 & 7.08 & 8.61 & 0 & 1.25 \\
\hline Overall & -2.2 & -5.8 & 0.56 & 2.38 & 0 & 1.56
\end{tabular}

Notes: Figures above represent medians and means within each quintile of the distribution of percent change in sustainable consumption. The first two columns show the quintile-specific medians and means of percent changes in sustainable consumption. The third and fourth columns give the median and mean number of years by which respondents would have to delay retirement to maintain pre-crash sustainable consumption levels. The last two columns give the median and mean number of years by which respondents reported delaying retirement "as a result of the economic crisis." Source: Author's calculations based on CogEcon data.

fifth, or most affected, quintile. This result is suggestive of an inverse-U shaped reaction of retirement age to wealth losses, and the motivation for inclusion of a quadratic term in the regression analysis.

Regression Analysis.-The first column of Table 2 reports the Tobit estimation results from the specification described in equation (1). Consistent with expectations based on a life cycle model with retirement choice, the coefficient on $\Delta R_{j, S C 08}$, the number of additional years a respondent would need to work to recoup losses, is positive, though not statistically significant at standard levels. The coefficient on the quadratic term is negative and statistically significant at the 10 percent level.

The average marginal effect of $\Delta R_{j, S C 08}$, 0.084 (s.e. 0.054), implies that respondents adjust retirement age by an average of only 8.4 percent of the change that would be needed to maintain pre-crash sustainable consumption levels after the crash. For the average value of $\Delta R_{j, S C 08}$ of 2.4 years, the implied adjustment of retirement age is just under 2.5 months. Meanwhile, for the median value of $\Delta R_{j, S C 08}$ of 0.6 years, the implied adjustment of retirement age is approximately 2.5 weeks.

The second column of Table 2 reports results from an extension including an indicator variable for "stock market pessimism" and also interacting this indicator variable with the
$\Delta R_{j, S C 08}$ variables. The stock market pessimism indicator is equal to 1 if respondents answered that there was less than a 50 percent chance that the stock market would be higher in one year than it was on the day they completed the postcrash survey, and zero otherwise.

TABLE 2-TOBIT REGRESSION RESULTS WITH CHANGE IN REPORTED RETIREMENT AGE AS DEPENDENT VARIABLE

\begin{tabular}{lcc}
\hline \hline & $(1)$ & $(2)$ \\
\hline$\Delta R_{j, S C 08}$ & 0.275 & $-0.745^{*}$ \\
& $(0.168)$ & $(0.434)$ \\
$\left(\Delta R_{i, S C 08}\right)^{2}$ & $-0.013^{*}$ & 0.038 \\
& $(0.007)$ & $(0.030)$ \\
$I_{\text {stock pessimism }}$ & & 0.650 \\
$I_{\text {stock pessimism }} \times \Delta R_{j, S C 08}$ & & $(1.042)$ \\
& & $1.182^{* *}$ \\
$I_{\text {stock pessimism }} \times\left(\Delta R_{j, S C 08}\right)^{2}$ & & $(0.512)$ \\
Sigma & & $-0.058^{*}$ \\
& & $(0.033)$ \\
Observations & $6.255^{* * * *}$ & $5.015^{* * *}$ \\
Uncensored observations & $(0.982)$ & $(0.496)$ \\
& 306 & 279 \\
& 124 & 113
\end{tabular}

Notes: Results are from Tobit regressions conducted using individual-level sampling weights from the CogUSA study. Constant omitted to conserve space. Robust standard errors reported in parentheses. * Significant at the 10 percent level. ** Significant at the 5 percent level. $* * *$ Significant at the 1 percent level.

Here, the coefficients on the interaction terms indicate a statistically-significant inverse 
U-shaped relationship between $\Delta R_{j, S C 08}$ and changes in retirement age when respondents are pessimistic about the stock market. The average marginal effect of $\Delta R_{j, S C 08}$ for pessimistic respondents is 0.154 (s.e. 0.092), statistically significant at the 10 percent level. This is about twice the effect size found the previous regression. For optimistic respondents, the average marginal effect is -0.225 (s.e. 0.137), also statistically significant at the 10 percent level. These results suggest that stock market pessimism magnifies the effect of wealth losses, almost doubling the implied changes in retirement age from the previous regression.

\section{Discussion}

A simple life cycle model with retirement choice predicts that unexpected changes in wealth will cause changes in retirement plans. However, literature using stock market movement in the 1990s and early 2000s on to study the effects of wealth shocks on retirement timing has found mixed results. On the one hand, Julia Coronado and Maria Perozek (2003) found that individuals holding stock at the beginning of the bull market of the 1990s retired an average of several months earlier than other individuals, and Sevak (2002) estimated that an asset gain that would allow sustainable consumption to double decreased retirement age by 1.25 years. On the other hand, studies by Michael Hurd and Monica Reti (2001) found no difference in retirement expectations between stockholders and nonstockholders, and Courtney Coile and Phillip Levine (2006) concluded that the stock market did not cause changes in aggregate labor supply.

This study, focusing instead on wealth losses during late 2008 and early 2009, provides evidence that stock and real estate wealth losses during the Great Recession may have caused delays of planned retirement age, at least for those who are able to remain employed. Regression estimates presented here imply effects on the order of a few weeks for an older American with a median wealth loss, and a few months for an older American with an average wealth loss. While the estimated effect sizes are not large, they line up closely with the average retirement delay of 1.5 months predicted by Alan Gustman, Nahid Tabatabai and Thomas Steinmeier (2009) from a structural simulation of the expected impact of the recent stock market losses on older Americans. Also consistent with predictions from a life cycle model with retirement, stock market pessimism, a measure of how permanent respondents consider their losses to be, is associated with larger estimated effects of wealth losses on planned retirement age.

\section{REFERENCES}

Coile, Courtney C. and Phillip B. Levine. 2006. "Bulls, Bears and Retirement Behavior." Industrial and Labor Relations Review, 59(3): 408-429.

Coronado, Julia Lynn and Maria G. Perozek. 2003. "Wealth Effects and the Consumption of Leisure: Retirement Decisions During the Stock Market Boom of the 1990s" FEDS Working Paper 2003-20.

Gustman, Alan L., Thomas L. Steinmeier, and Nahid Tabatabai. 2009. "What the Stock Market Decline Means for the Financial Security and Retirement Choices of the NearRetirement Population." National Bureau of Economic Research Working Paper 15435.

- . 2010. Pensions in the Health and Retirement Study. Cambridge, MA: Harvard University Press.

Hurd, Michael and Monika Reti. 2001 "The Effects of Large Capital Gains on Work and Consumption: Evidence from Four Waves of the HRS," RAND Labor and Population Program Working Paper 03-14.

Mitchell, Olivia S., James M. Poterba, Mark J. Warshawsky, and Jeffrey R. Brown. 1999. "New evidence on the money's worth of individual annuities." American Economic Review, 89(5): 1299-1318.

Social Security Administration. 2006. Period life table. http://www.ssa.gov/OACT/STATS/ table4c6.html.

Sevak, Purvi. 2002. "Wealth shocks and retirement timing: Evidence from the nineties." Michigan Retirement Research Center Working Paper 2002-027. 